использования можно видеть в различных формах: графических, словесных, табличных, математических и многих других. Чем точнее информационная модель, тем более качественно и полно она отображает совокупность свойств оригинального объекта. Поэтому необходимо выделить только самые необходимые параметры для моделирования и установить связи между ними. Этот процесс называется системным анализом.

Когда информационная модель сформирована, ее параметры можно использовать для изучения реального объекта, прогнозирования его поведения в различных условиях, проведения расчетов. Часто задействуют смешанные информационные модели. Примеры использования такой формы моделирования часто можно встретить в строительстве, когда формируются и отражаются отдельные характеристики сложного объекта, например, здания, в виде чертежей, математических расчетов прочности и допустимых нагрузок. Еще одним ярким примером смешанной информационной модели служит географическая карта c eе топографическими символами, надписями, таблицами. Такая модель может также представляться в виде графиков, диаграмм, таблиц, схем. Последние условно разделяются на карты, блоксхемы и графы[4].

К информационным относят и вербальные модели, которые представляются в разговорной или мысленной форме. Они еще имеют название "словесные информационные модели". Примеры такого моделирования можно наблюдать при управлении автомобилем: ситуация на дороге, показания светофоров, скорость соседних автомобилей и т. д. анализируются человеком. При этом вырабатывается определенная модель поведения. Если текущая ситуация смоделирована правильно, то данный отрезок пути будет безопасным. Если нет, велика вероятность аварии.

$$
* * *
$$

1- «BPwin и ERwin : CASE-средства разработки информационных систем», 2001г, Маклаков С.В.

2- «Моделирование систем и процессов», 2015г, В.Н. Волкова, В.Н.Козлова.

3- «Математическое моделирование» ,2007г, Сидоров В.Н., Ахметов В.К.

4- «Книга диаграмм. Визуальное решение задач.», 2016г, Кевин Дункан.

\title{
Скрипина И.И. \\ Анализ преимуществ использования сетей с большим радиусом действия и низким энергопотреблением
}

Белгородский государственный национальный исследовательский университет (Россия, Белгород)

doi: $10.18411 / l j-31-01-2018-60$

idsp: 000001:lj-31-01-2018-60

\section{Аннотация}

В статье рассмотрены ключевые аспекты использования сетей с большим радиусом действия и низким энергопотреблением. Проанализированы основные характеристики различных сетей и выявлены приоритетные. Определенны экономические последствия внедрения рассмотренных технологий.

Ключевые слова: LoRaWAN, , беспроводныетехнологии, LPWAN, энергоэффективность, протокол

\section{Abstract}

The article considers the key aspects of the use of high-range and low power consumption. The basic characteristics of the different networks and identified priorities.Certaineconomicimpactsofimplementationofconsideredtechnologies.

Keywords: LoRaWAN, , wireless technologies, LPWAN, energy efficiency, protocol 
В настоящее время все большее развитие получает тема использования маломощной радиосвязи (менее 25 мВт), поскольку она дает возможность не только использовать безлицензионные диапазоны, но и передавать низкоскоростные данные на расстояния до 50 км.

B основе таких сетей лежит технология LPWAN - суть ее в передаче данных с низким энергопотреблением, она создана для беспроводной передачи телеметрии междудатчикам машинной информации на большие расстояния.

Ярким представителем такой связи можно смело назвать созданный в 2015г. открытый энергоэффективный сетевой протокол LoRaWAN (LongRangeWideAreaNetworks), имеющий неоспоримые преимущества перед Wi-Fi и сотовыми сетями благодаря возможности развертывания межмашинных (M2M) коммуникаций.Использование таких сетей нашло широкое применение в так называемом «Интернете вещей»(IоT).

IоT - система объединенных компьютерных сетей и подключенных физических объектов со встроенными датчиками и программным обеспечением для сбора и обмена данными с возможностью удаленного контроля и управления без участия человека.

Сферы применения данных сетей разнообразны и экономически выгодны, примерами могут служить:

1) мониторинг ДТП и вызов экстренных служб;

2) погодные датчики;

3) контроль шума;

4) «умные светофоры»;

5) учет ресурсов и т.д.

Рассмотрим более подробно несколько конкретных решений сетей и их технологические характеристики.

Таблица 1.

Таблииа технологических характеристик конкретных решений сетей.

\begin{tabular}{|c|c|c|c|c|c|c|c|}
\hline $\begin{array}{l}\text { № } \\
\text { № } \\
\end{array}$ & $\begin{array}{c}\text { Технические } \\
\text { характеристики }\end{array}$ & $\begin{array}{c}\text { LoRaWA } \\
\mathrm{N} \\
\end{array}$ & Стриж & SigFox & Nuel & Nware & Dash7 \\
\hline 1. & Дальность & $\begin{array}{c}\text { В } \\
\text { городской } \\
\text { черте до } 5 \\
\text { км., вне } \\
\text { города до } \\
50 \text { км. }\end{array}$ & $\begin{array}{l}\text { В городской } \\
\text { черте до } 5 \\
\text { км., вне } \\
\text { города до } 40 \\
\text { км. }\end{array}$ & $\begin{array}{c}\text { В } \\
\text { городской } \\
\text { черте до } 7 \\
\text { км., вне } \\
\text { города до } \\
50 \text { км. }\end{array}$ & До 10 км. & До 10 км. & $\begin{array}{c}\text { До } 1 \\
\text { км.в } \\
\text { городск } \\
\text { ой } \\
\text { черте. }\end{array}$ \\
\hline 2. & Частота & $\begin{array}{c}\text { Менее } \\
1 Г Г Ц ~\end{array}$ & 868,9МГЦ & $\begin{array}{c}\text { Частотно } \\
\text { независи } \\
\text { мая сеть }\end{array}$ & ISM & Менее 1ГГЦ & 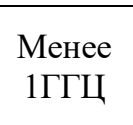 \\
\hline 3. & $\begin{array}{l}\text { Скорость } \\
\text { передачи }\end{array}$ & $\begin{array}{c}\text { 0,3-50 } \\
\text { кбит/с., } \\
\text { адаптивн } \\
\text { о }\end{array}$ & 50 кбит/с. & $\begin{array}{l}10-1000 \\
\text { бит/c. }\end{array}$ & 100 кбит/с. & 100 бит/с. & $\begin{array}{c}167 \\
\text { кбит/с. }\end{array}$ \\
\hline 4. & Протокол & $\begin{array}{c}\text { Открыты } \\
\text { й }\end{array}$ & $\begin{array}{c}\text { Проприетар } \\
\text { ный }\end{array}$ & $\begin{array}{c}\text { Открыты } \\
\text { й }\end{array}$ & $\begin{array}{c}\text { Проприетар } \\
\text { ный }\end{array}$ & $\begin{array}{c}\text { Проприетар } \\
\text { ный } \\
\end{array}$ & $\begin{array}{l}\text { Открыт } \\
\text { ый }\end{array}$ \\
\hline 5. & $\begin{array}{c}\text { Потребление } \\
\text { электроэнергии }\end{array}$ & Низкое & Низкое & Низкое & Низкое & Низкое & Низкое \\
\hline 6. & $\begin{array}{c}\text { Аутентификаци } \\
\text { я }\end{array}$ & Да & Да & Да & - & Да & Да \\
\hline 7. & $\begin{array}{c}\text { Е2E } \\
\text { шифрование }\end{array}$ & Да & Да & Да & - & Да & Да \\
\hline 8. & $\begin{array}{c}\text { Полная } \\
\text { двунаправленн } \\
\text { ость }\end{array}$ & $\begin{array}{c}\text { Да, в } \\
\text { зависимос } \\
\text { ти от } \\
\text { режима } \\
\end{array}$ & Да & Нет & Да & Нет & Да \\
\hline 9. & $\begin{array}{l}\text { Поддержка } \\
\text { сенсоров }\end{array}$ & Да & Да & Нет & - & Нет & Да \\
\hline
\end{tabular}




\begin{tabular}{|c|c|c|c|c|c|c|c|}
\hline & $\begin{array}{c}\text { движущихся } \\
\text { между } \\
\text { станциями }\end{array}$ & Да & $\begin{array}{c}\text { Триангуляци } \\
\text { я RSSI }\end{array}$ & Нет & - & Нет & Да \\
\hline 10. & $\begin{array}{c}\text { Местонахожден } \\
\text { ие сенсора }\end{array}$ & Да & Да & Да & Да & Да & Да \\
\hline 11. & $\begin{array}{c}\text { Масштабируем } \\
\text { ость }\end{array}$ & Да &
\end{tabular}

Проанализировав представленную выше таблицу можно сделать вывод, что LoRaWAN имеет ряд преимуществ, таких как: высокую скорость передачи; низкое потребление энергии; достаточно большую дальность даже в условиях городской черты; поддержку различных видов сетей, а также экономическую эффективность использования данного вида сети.

Если остановиться более подробно на экономической эффективности можно выделить следующие возможности,с помощью которыхможно получить значительные выгоды от применения таких технологических решений:

1) повышение надежности используемых технологий;

2) сокращение затрат;

3) появление новых рынков сбыта и т.д.

По оценке проведенной AO «PricewaterhouseCoopers - аудиторская сеть», кумулятивный экономический эффект от внедрения IоТ в городской среде в период до 2025 года может достичь 375 млрд рублей[]. Такие высокие показатели складываться из оптимизации транспортной системыгородов; снижения затрат населения на ЖКХ; улучшения работ коммунальных служб; сокращения затрат в сфере энергоресурсов, и сокращению затрат населения на энергоресурсы; повышению уровня жизни и расходов на здравоохранение.

Рост заинтересованности в использовании таких сетей со стороны не только бизнеса, но и государства закономерен: экономическая привлекательность, социальная направленность, перспективность развития, экономия за счет снижения затрат. Все это можно считать основой для дальнейшего широкого использования рассматриваемых технологий.

$$
* * *
$$

1. ГОСТ 15150-69 Межгосударственный стандарт. Машины, приборы и другие технические изделия. Исполнения для различных климатических районов. Категории, условия эксплуатации, хранения и транспортирования в части воздействия климатических факторов внешней среды-введ. 1971.01.01, Москва: Стандартифнорм 2010, 58c.

2. Оконечное оборудование LoRaWAN [Электронныйресурс]/ Электрон. Текстовые дан. - Москва: 2016. Режим доступа http://loralink.ru/equipment/terminal.html, свободный

3. PwC Россия [Электронный ресурс]/ Электрон. Текстовые дан.-Москва: 2017. Режим доступа https://www.pwc.ru/ru/about.html, свободный

4. Lo-Ra.ru Сообщество разработчиков LoRaLoRa WAN LPWAN [Электронный ресурс]/ Электрон. текстовые дан. -Москва: 2017. Режим доступа http://lo-ra.ru/lora, свободный

\section{Чулюков В.А. \\ Модель организационного управления образовательной системой: обеспечивающая компонента}

Воронежский Государственный педагогический университет

doi: 10.18411/lj-31-01-2018-61

(Россия, Воронеж)

idsp: 000001:lj-31-01-2018-61

Аннотация
Описывается составляющая системной структуры (обеспечивающая компонента)
модели организационного управления образовательного учреждения высшего

